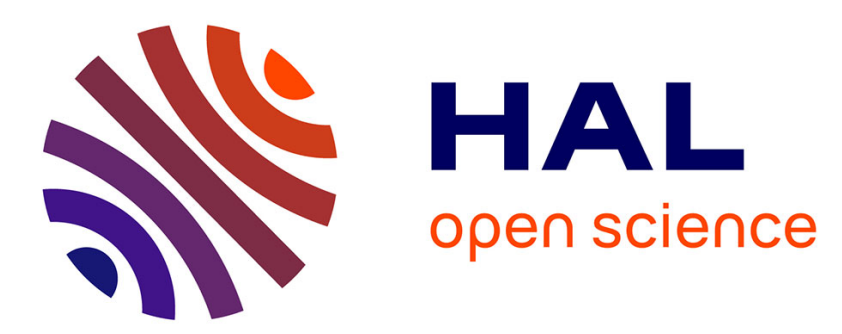

\title{
Structuralist Praxeologies as a Research Program on the Teaching and Learning of Abstract Algebra
}

\author{
Thomas Hausberger
}

\section{To cite this version:}

Thomas Hausberger. Structuralist Praxeologies as a Research Program on the Teaching and Learning of Abstract Algebra. International Journal of Research in Undergraduate Mathematics Education, 2018, 4 (1), pp.74-93. 10.1007/s40753-017-0063-4 . hal-01668169

\section{HAL Id: hal-01668169 \\ https://hal.science/hal-01668169}

Submitted on 20 Feb 2021

HAL is a multi-disciplinary open access archive for the deposit and dissemination of scientific research documents, whether they are published or not. The documents may come from teaching and research institutions in France or abroad, or from public or private research centers.
L'archive ouverte pluridisciplinaire HAL, est destinée au dépôt et à la diffusion de documents scientifiques de niveau recherche, publiés ou non, émanant des établissements d'enseignement et de recherche français ou étrangers, des laboratoires publics ou privés. 


\title{
Structuralist praxeologies as a research program on the teaching and learning of Abstract Algebra
}

\author{
Thomas Hausberger
}

Received: date / Accepted: date

\begin{abstract}
Research reported in this article has been conducted from the theoretical perspective of the Anthropological Theory of the Didactic developed by Y. Chevallard and his collaborators, and from the institutional perspective of university mathematics education in France. It focuses on the teaching and learning of algebraic structures. The article introduces the notion of structuralist praxeology in the theory of teaching and learning of Abstract Algebra. The notion is illustrated by detailed descriptions of structuralist praxeologies related to the arithmetic of abstract rings, identified, on the one hand, in the history of mathematics and in Abstract Algebra textbooks and, on the other, in interactions among a group of learners of Abstract Algebra on an online discussion forum. The theoretical (and practical) issues in the teaching and learning of the structuralist praxeologies are discussed in the context of the difficulties that learners experience in the transition from undergraduate and graduate studies in mathematics at university. The article concludes with an outline of a research program based on further praxeological analyses of the tasks, methods, methodologies and theories characteristic of structuralist thinking in a teaching and learning environment.
\end{abstract}

Keywords Abstract Algebra · praxeologies · algebraic structuralism · Anthropological Theory of the Didactic

Résumé Cet article rend compte d'une recherche menée dans la perspective théorique de la Théorie Anthroplogique du Didactique développée par Y. Chevallard et ses collaborateurs, et dans le contexte institutionnel de l'enseignement supérieur en France. Le sujet d'étude est l'enseignement et l'apprentissage des structures algébriques. L'article introduit la notion de praxéologie structuraliste en didactique de l'algèbre abstraite. Le propos est illustré en détaillant les praxéologies structuralistes en arithmétique des anneaux abs-

T. Hausberger

Institut Montpelliérain Alexander Grothendieck, CNRS, Univ. Montpellier

E-mail: thomas.hausberger@umontpellier.fr 
traits, sur la base d'une étude historique et de manuels, d'une part, et à travers l'étude des interactions d'un groupe d'apprenants sur un forum de mathématiques d'autre part. Les enjeux didactiques de la notion de praxéologie structuraliste sont discutés en relation avec les difficultés identifiées dans l'enseignement et l'apprentissage de l'algèbre abstraite, à la transition entre Licence et Master de mathématiques à l'université. Enfin, l'article trace les grandes lignes d'un programme de recherches fondé sur la poursuite des analyses des tâches, des méthodes, méthodologies et théories caractéristiques de la pensée structuraliste dans un contexte d'enseignement-apprentissage.

\section{Introduction}

The difficulties related to the teaching and learning of Abstract Algebra at university (the theories of algebraic structures, in particular Group, Ring and Field Theories) are acknowledged by many authors (Leron \& Dubinsky, 1995; Nardi, 2000; Durand-Guerrier et al., 2015). They reflect a "transition problem" (Gueudet, 2008) which, in comparison to the secondary-tertiary transition, occurs inside the university curriculum, at the transition between undergraduate ("Licence") and graduate ("Master") studies in mathematics at university.

Several explanatory factors are linked to the particular epistemological nature of the taught knowledge, in relation to what I called "the challenge of structuralist thinking" (Hausberger, 2012) and its didactic consequences that may be analysed within the epistemological framework of FUGS (formalising, unifying, generalizing, simplifying) concepts (Robert, 1987; Dorier, 1995). A new fact in comparison to the case, investigated by Dorier, of the teaching and learning of Linear Algebra at the undergraduate level (the vector space structure being the first algebraic structure that students meet and study), is the following: unification becomes, as stressed in (Hausberger, 2012), multilevel.

At level 1, the same theory applies to objects of different nature; at level 2, the axiomatic presentation of structures allows a unified treatment (the same types of questions are raised about the different structures, and mathematicians try to solve them with the same types of tools), highlighting the bridges between these structures; at level 3, what has been previously a form (the structures) becomes fully an object belonging to a higher level of organisation, Category Theory or another meta-theory of structures. If level 3 can hardly be approached realistically before the second year of a graduate programme, the challenge of structuralist thinking is situated at level 2 and is pinpointed in Abstract Algebra textbooks in the line of van der Waerden (1930). These textbooks reflect the application of a method, "the structuralist method" (see below); structuralist thinking may be regarded as a methodology.

I have thus conducted the research reported here from the theoretical perspective of the Anthropological Theory of the Didactic developed by Y. Chevallard and his collaborators (Bosch \& Gascón, 2014), on the basis of the methodological dimension of structuralist thinking and the consideration of the transition problem as an institutional-depending phenomenon. In order to 
investigate this phenomenon, the article introduces the notion of structuralist praxeology in the theory of teaching and learning of Abstract Algebra. It should be noted that, if structuralist thinking much inspired psychologists (e.g. Piaget (1989)) whose accounts in turn fostered further developments in Mathematics Education (Dubinsky, 1991; Sfard, 1991) of a cognitive nature, our concern here will remain epistemological (in the sense of the historical epistemology of G. Bachelard) and institutional (in the sense of ATD). Further connections between structuralism and psychological approaches in Mathematics Education are discussed in Hausberger (2017b, section 2). In this paper, the notion of structuralist praxeology is illustrated by detailed descriptions of structuralist praxeologies related to the arithmetic of abstract rings, identified, on the one hand, in the history of mathematics and in Abstract Algebra textbooks and, on the other, in interactions among a group of learners of Abstract Algebra on an online discussion forum. The article concludes with an outline of a research program based on further praxeological analyses of the tasks, methods, methodologies and theories characteristic of structuralist thinking in a teaching and learning environment.

It should be noted that this article is a revised and enlarged version of a communication presented in French at INDRUM 2016 (Hausberger, 2016d). It aims at the international dissemination, especially outside the francophone community, of the notion of structuralist praxeology and its associated line of research. In comparison with (Hausberger, 2016a), also written in French, it offers a more precise description of structuralist praxeologies in terms of ATD formalism and deeper insight on its use as an analytic tool, but does only outline briefly the ecological ${ }^{1}$ question (Barquero, Bosch, \& Gascón, 2013), that is to say the study of the conditions and constraints that may hinder or foster the development of such praxeologies in an educational context, which is the main question raised in loc. cit.

\section{Theoretical Framework}

The Anthropological Theory of the Didactic pursues the "scientific study of how bodies of knowledge percolate through human groups" (Chevallard, 2006). It "postulates that any activity related to the production, diffusion, or acquisition of knowledge should be interpreted as an ordinary human activity, and thus proposes a general model of human activity built on the key notion of praxeology" (Bosch \& Gascón, 2014). According to Chevallard (2006):

one can analyse any human doing into two main, interrelated components: praxis, i.e. the practical part, on the one hand, and logos, on the other hand. [They are interrelated on the principle that] no human action can exist without being, at least partially, "explained", made "intelligible", "justified", "accounted for", in whatever style of "rea-

\footnotetext{
${ }^{1} \mathrm{~A}$ metaphor from biology in which bodies of knowledge are seen as living entities that develop inside institutions.
} 
soning" such an explanation or justification may be cast. Praxis thus entails logos which in turn backs up praxis.

The praxis part of the praxeology consists of a type of tasks $T$ together with a corresponding technique $\tau$ (useful to carry out the tasks $t \in T$ in the scope of $\tau)$. The logos part includes two levels of description and justification: the technology $\theta$, i.e. a discourse on the technique, and the theory $\Theta$, which often unifies several technologies. In short, the praxeology, as basic unit of human activity, is represented by a quadruple $[T / \tau / \theta / \Theta]$. Such elements may be gathered in a local praxeology, that is to say a set of praxeologies in the previous sense (now called point praxeology to prevent any confusion) organised around a common technological discourse. Finally, a regional praxeology contains point or local praxeologies sharing a common theory. These notions will be illustrated in next sections in the context of Abstract Algebra.

While Abstract Algebra often appears, from the perspective of the learner, as a set of isolated questions and tasks which one may solve depending on whether one knows the "trick" or not, I make the hypothesis that clarifying structuralist techniques and their associated technological discourse may inform practices in Abstract Algebra, show their rationale and ground their unity. Barbe, Bosch, Espinoza, and Gascón (2005) show how the epistemological dominant model of Calculus in high schools determines the mathematical praxeologies dedicated to the study of limits of functions. Similarly, in the context of Abstract Algebra, it is to investigate how the epistemological model of mathematical structuralism impacts praxeological organisations in the teaching of algebraic structures and problem-solving in Abstract Algebra.

The elaboration of a reference epistemological model (Florensa, Bosch, \& Gascón, 2015) as sequences of praxeologies, for a given body of knowledge, is an important step in any research carried out in the ATD framework. It is the tool that will be used by the researcher to describe, analyse, put in question or design the specific contents that are at the core of a teaching and learning process. In order to build such a model, "mathematical praxeologies are described using data from the different institutions participating in the didactic transposition process, thus including historical, semiotic and sociological research, assuming the institutionalized and socially articulated nature of praxeologies" (loc. cit. p. 2637). At university level, the didactic transposition, that is the "transformations applied to a content or a body of knowledge since it is produced and put into use, until it is actually taught and learned" (Bosch \& Gascón, 2014, p. 70), takes place in a single generic institution - University - but across time and space in history. I will therefore construct my notion of structuralist praxeology from a historical and epistemological study of structuralist thinking and structuralist practices, combined with a study of a few textbooks that are widely used in my educational context (French universities).

In particular, the elaboration of a reference praxelogical model for Algebra will be useful to clarify the transition problem raised by this topic, in the spirit of the work of Winsløw (2008). Indeed, Winsløw sees the transition 
from Calculus to Real Analysis at university as a transition from the concrete (e.g. differentiation and integration of given functions) to the abstract (general theorems on limits, continuity and differentiability) which is reflected, on the praxeological level, by the development of new praxeologies whose praxis part is built on the logos part of a praxeology that the students have previously encountered. If abstract algebra comes from a conceptual rewriting of classical algebra (the study of polynomial equations and the problem of their solvability) according to the structuralist methodology (see next section), how is this rewriting translated into praxeological terms? What kind of institutional phenomenon does the lens of structuralist praxeology allow to see at the transition between undergraduate and graduate studies in mathematics?

These questions will be addressed in the sequel. Further considerations on ATD as a research programme in relation to university mathematics education may be found in Winsløw et al. (2014).

\section{The epistemological genesis of structuralist thinking in mathematics}

In this section, I will give a quick survey of mathematical structuralism, on the basis of the work of historians and philosophers (Corry, 1996; Benis-Sinaceur, 2010) and in quest of the "raison d'être" of algebraic structures. More details may be found in (Hausberger, 2017b, to appear). The goal is to bring to light the anthropological roots of mathematical structuralism in order to be able to build in the next section a praxeological model of reference for the actual mathematical practise in Abstract Algebra.

The notion of mathematical structure originates from the constitution of mathematics as the science of "relations between objects", an abstract relational viewpoint that dominates contemporary mathematics since the development of formal axiomatics, most notably by Hilbert. Structuralist thinking is characterised by a specific style and methodology that collected a following around Noether in the 1920s. This school changed the way one proves theorems, focusing on general proofs that limit the calculations and put forward the concepts. The goal behind the definition of new concepts is to rebuild a mathematical domain on a new basis, on more fundamental concepts, more general and more "simple":

We have to try to reduce a mathematical domain to its most general fundamental concepts, hence the simpler, and build and rebuild using these sole concepts (Hasse, 1930, pp.26-27, my translation).

This project of mathematical re-foundation also contains a didactic dimension (allowing the intelligibility of a highly-structured content). This reconstruction brings a new vision of mathematics as a discipline and paves the way for unprecedented mathematical constructs, new mathematical objects. Hasse's quote is also interesting by highlighting generality, adopted as a principle (the quest for a maximum degree of generality) on the claim that it induces 
simplification. This view, emblematic of the structuralist project as it is, was debated within the mathematical community; thus, for Mandelbrojt:

There is a moment when all the objects to which it applies convey the meaning of the theorem itself. [...] This is the path to explanatory generality. I personally feel that there is an optimum to this generality (Mandelbrojt, 1952, pp.426-427, my translation).

The rationale for the concepts are thus to be found in the examination of the proofs, making them appear as "springs" of the proofs (in the analysis phase). Mathematicians then elaborate a deductive theory, by taking these principles separately and then combining them to produce fertile axiomatic systems (such as the axiomatic definition of a group) in such a way that the theorems on the objects under consideration will appear as logical consequences of these systems (synthesis phase). This process of constitution of structuralist concepts is well described in the Bourbaki Manifesto (Bourbaki, 1950), written by a group of French mathematicians (Beaulieu, 1993) who were the great promoters of structuralist thinking, and who set out to apply the methodology developed by the German algebraists to all fields of mathematics.

Bourbaki evokes the applicative scope of the structuralist method, applied to new problems, in a section entitled "The standardization of mathematical techniques":

It should be clear from what precedes that its most striking feature is to effect a considerable economy of thought. The "structures" are tools for the mathematician; as soon as he has recognized among the elements, which he is studying, relations which satisfy the axioms of a known type, he has at his disposal immediately the entire arsenal of general theorems which belong to the structures of that type. Previously, on the other hand, he was obliged to forge for himself the means of attack of his problem; their power depended on his personal talents and they were often loaded down with restrictive hypotheses, resulting from the peculiarities of the problem that was being studied. One could say that the axiomatic method is nothing but the "Taylor system" for mathematics (Bourbaki, 1950, p. 227).

Bourbaki's discourse is clearly technological, in the sense of ATD (see section 2): it accounts for a method and makes it intelligible, it explains and justifies the techniques. All the ingredients to define praxeologies are therefore present in the Bourbaki Manifesto. However, to remain faithful to the spirit of the method, the types of tasks must not remain at the theoretical level (i.e. within the abstract axiomatic game) but catch concrete objects and show the gains of the conceptual abstraction. As we will see later, this entails a difficulty linked to the presence of basic methods that may hinder the development of structuralist praxeologies. 


\section{Exemplification of structuralist praxeologies in the case of Ring Theory}

I will now propose an epistemological model of reference for the arithmetic of abstract rings and begin its formalisation in praxeological terms. This model will be applied to the analysis of the data presented in the next section (the mathematical online forum). I will conclude by giving a general characterisation of structuralist praxeologies.

\subsection{Towards a praxeological model of reference}

The arithmetic of $\mathbb{Z}$ and that of the rings of integers of number fields (see below), under successive generalisations, was one of the main sources in the gradual historical progression towards the construction of Ring Theory as an abstract structuralist theory. Several major properties of rings have been highlighted and gave birth to the now standard large classes of rings: Euclidean rings, principal ideal domains (PID), and unique factorisation domains (UFD). The mathematical stake is the following: what is the analogue of $\mathbb{Z}$ if we replace $\mathbb{Q}$ by a finite extension of $\mathbb{Q}$ (i.e. a number field)? We want the Fundamental Theorem of Arithmetic to be true (existence and uniqueness of the prime factorisation). But this is not always the case, even for the "good concept" of the ring of integers. This negative result led Dedekind to introduce ideals: in rings of integers, every ideal is as a product of prime ideals.

Another branch that has historically contributed is the arithmetic of polynomials, developed by Hilbert, although the latter had not made the connection with number fields: it was not until the 1920s, under the influence of Noether, that the significance of structures as organising principle was fully understood. Unification is then carried out between Group Theory and Ring Theory, through the isomorphism theorems for instance (Hausberger, 2013, $2017 \mathrm{a}$, to appear), which highlights the benefice of a unified treatment of structures and led to the refoundation of both theories according to the structuralist method.

The Gaussian integers $\mathbb{Z}[i]$ and $K[X]$ thus appear as the two great paradigmatic examples to unify. Some books, e.g. (Guin, 2013), focus on $K[X]$ according to the argument that such a ring satisfies a universal property (a Category Theory perspective). From another point of view, $\mathbb{Z}[i]$ generates a class of examples (the rings of integers) that can be treated with similar techniques, thus generates types of tasks.

The notions of ring, homomorphism and ideals are a "theoretical background" in which fits the theory of Euclidean rings, PIDs and UFDs. Many authors, e.g. (Guin, 2013, Chap. I), thus precede this chapter with a chapter on "generalities on rings", which is very abstract (no problems on concrete objects are brought forward) and relies on formal analogies between groups and rings in the structuring of the theory: for example, normal subgroups and ideals are the kernels of homomorphisms. Other authors, e.g. Colmez (2011), go further 
and present, in a first chapter with a title like "mathematical vocabulary", all the usual mathematical structures (not restricting to algebra) and the standard structuralist constructs (sub-structures, morphisms, kernels and images, products or sums, quotients, etc.). This is thought of as a prerequisite in order to tackle more contemporary mathematical stakes in a wide range of mathematical domains. The concepts and theorems highlighted in such chapters typically constitute, in my approach, structuralist techniques and technologies to identify and relate tasks in Abstract Algebra which concern more concrete mathematical objects.

I give below a list of types of tasks that frequently appear in the handouts and textbooks that I consulted (e.g. Guin, 2013; Perrin, 1996):

- $T_{1}^{+}$(resp. $T_{2}^{+}, T_{3}^{+}, T_{4}^{+}$): show that a given ring is an integral domain (resp. a UFD, PID, Euclidean ring), and its negation $T_{1}^{-}$(resp. $T_{2}^{-}, T_{3}^{-}, T_{4}^{-}$).

- $T_{5}$ : determine the group of units $A^{\times}$of a given ring $A$.

- $T_{6}$ : determine the set of irreducible elements of a given ring $A$, or simply show that a given element is irreducible, or compute the decomposition of a given element into irreducible factors. These three types of tasks are related by a common logos on irreducibility in abstract rings, but the techniques may vary depending on $A$ (for instance, the use of the "norm", in the sense of number theory, in the case of number fields). The statement and ambition of the tasks assigned depend on the techniques which are available to students.

$-T_{7}$ : compute the greatest common divisor of two given elements.

It is important to note that the mathematical domain at stake is characterised by a particular ecological structure in the form of a chain of inclusions of the different classes of rings: Fields $\subset$ UFD $\subset$ PID $\subset$ Euclidean rings, which impacts the types of tasks and the corresponding techniques. Delineating these classes, and thus the extension of the concepts, is an important part of the tasks assigned to the students (Guin, 2013, pp. 55-56), (Perrin, 1996, p. 63).

Working out the tasks also requires a switch to a set-theoretic mode of thinking, and the linking of properties and operations on elements with corresponding properties and operations on sets, as a real "dictionary" that I call the "elements/structure dictionary": for example, $a$ is a prime if and only if the ideal $(a)$ is prime (and not reduced to $(0)$ ), the gcd is related to the sum of ideals, etc. Once the situation is transferred to the level of structures, a second kind of dictionary may be used, that relates properties of an ideal $I$ (of a ring $A$ ) and properties of the induced quotient $A / I$ : e.g. $I$ is prime (resp. maximal) if and only $A / I$ is an integral domain (resp. a field). This legacy of Dedekind and Noether represents a major conceptual leap. In (Hausberger, 2013, 2017a, to appear), I connect the transition problem generated by the access to structuralist algebra at university with the epistemological transition to this mode of thinking in terms of distinguished subsets and homomorphims which generates structuralist praxeologies. 
4.2 The case of type of task $T_{1}^{+}$(show that a given ring is an integral domain)

This task can be handled at different levels, depending on the structuralist dimension of the proof. Let's take the example of the ring $\mathbb{Z}[i]$ to illustrate this point.

At the first level (Level 1), it is shown that the definition of integral domain is satisfied, i.e. that "a product is zero if and only if one of the factors is zero". It is thus written $(a+i b)(c+i d)=0$, which leads to a somewhat tedious system to solve in the ring of integers, which may discourage many students. By contrast, when one realises that $\mathbb{Z}[i]$ is included in the set $\mathbb{C}$ of complex numbers, and that a nonzero element is invertible and therefore may be cancelled, the proof becomes "trivial": $z z^{\prime}=0$ with nonzero $z$ gives, by multiplying by $z^{-1}$, the nullity of $z^{\prime}$.

At Level 2, one still uses the inclusion $\mathbb{Z}[i] \subset \mathbb{C}$ but a general result (denoted $T h$ ) is invoked: any subring of a field is an integral domain. The technologicaltheoretical part, reduced at Level 1 to the properties of complex numbers, now integrates general abstract results, i.e. structures. It is this type of mathematical organisation that is targeted, not the mathematical organisation remaining at the level of the theory of objects.

At Level 3, it is invoked that a field is an integral domain and that the latter property remains valid for all subrings. This apparently invokes the same theoretical element as Level 2, but the wording of the response to the mathematical problem and its method of production (the heuristic) are different: a theorem is not simply applied, but the structuralist thinking is made explicit in relation to the question : it concerns the property that defines integral domains. One then thinks in terms of classes of objects, relationships between these classes (ring-field, in particular any integral domain may be embedded into a field) and property preservation under the structuralist operations on these classes (transition to a subring).

The distinction between level 2 and 3 may be clarified by formalising more precisely the preceding discourse in terms of praxeologies. Both levels rely on the same technique $\tau$ (embed the given ring $A$ in a field $K$ ), but the logos parts are different. At level 2, the technology $\theta_{2}$ consists in the theorem $T h$. At level 3, the technology may be described by two theorems: a field is an integral domain; every subring of an integral domain is an integral domain. Moreover, the theory also includes the following: any integral domain $A$ can be embedded into its field of fractions $K$, which is a more theoretical result and illuminates the scope of the technique. Altogether, the difference between both levels also reflects the fact that structuralist thinking is not only a method but also a methodology. The techniques are justified by the technological discourse but the logos part of the praxeology also explains how the set of techniques as a method have been developed according to the overall purpose described in the Bourbaki Manifesto. 
4.3 The case of type of task $T_{3}^{+}$(show that a given ring is a PID)

In the case of $\mathbb{Z}$, at Level 1 , the proof goes as follows: one takes a nonzero ideal $I$ of $\mathbb{Z}$ and considers $a=\inf (I \cap \mathbb{N})$. One shows that $I=a \mathbb{Z}$ using the Euclidean division. It is the same technique as the one used for the determination of the subgroups of $\mathbb{Z}$. Level 2 is to point out that the previous proof works whenever one has a generalisation of the Euclidean division: this amounts to perform $T_{3}^{+}$through $T_{4}^{+}$(show that a given ring is Euclidean).

Below will be discussed the task $T_{3}^{+}$in the case of the ring $\mathbb{D}$ of decimal numbers (the fractions the denominator of which are powers of ten). The first idea is to generalise the proof of $\mathbb{Z}$ (Level 1 ). One then realises that the "spring" of the proof resides in the relationship between $\mathbb{D}$ and $\mathbb{Q}$ : any subring of $\mathbb{Q}$ is a PID (another instance of Level 2). A learner having completed this path and adopted the new structuralist method will subsequently rely on this more concise and conceptual argument. It is also possible to show that $\mathbb{D}$ is Euclidean (thus perform $T_{3}^{+}$via $T_{4}^{+}$), by generalising to $\mathbb{D}$ the Euclidean division of $\mathbb{Z}$ on the basis of the writing of a decimal number as a fraction $x=a / 10^{n}, a \in \mathbb{Z}$ (with a similar Euclidean function $d(x)=|a|$; the key is the standard Euclidean algorithm on the numerators).

\subsection{Definition of structuralist praxeologies}

As we have seen, each type of task presents a dialectic (viewed here in the naive sense of a dynamic, a tension between two opposite poles) between the particular and the general, where one tries either to generalise (or adapt) known proofs, or to generalise the statement whose demonstration is at stake by hypothesising that the new statement is true and carries simplifications. Structuralist thinking is characterised by reasoning in terms of classes of objects, relationships between these classes and (structural) stability of properties under operations on structures.

Of the above examples, whenever Level 2 is reached (i.e. the logos includes a theorem on structures), we can talk about a structuralist praxeology. In general, such praxeologies aim at solving the task by raising the mathematical work to a level of generality that is the bearer of simplification and completing this work in support of the structuralist concepts and technological tools (combinatorial of structures, isomorphism theorems, structure theorems, etc.). Structuralist methodology aims at replacing a praxeology $[T, *, *, *]$ by a structuralist praxeology $\left[T^{g}, \tau, \theta, \Theta\right]$, where $T^{g}$ is a generalisation of $T$ that allows the use of structuralist techniques.

We will now observe this phenomenon in more detail through the work of a group of learners on a mathematical online forum. They interact without the intervention or guidance of a teacher. 


\section{Structuralist praxeologies as manifestations of structuralist thinking in exchanges among learners of Abstract Algebra}

The goal of this section is to give evidence that our epistemological model, based on expert mathematical practises, is also pertinent to analyse the actual mathematical activity in a learning environment. It will be an opportunity to apply the praxelogical model that has been previously constructed and to discuss an instance of the type of task $T_{3}^{-}$(show that a given ring is not a PID) that has not been exemplified yet. It will also serve as an illustration of the functioning of the particular-general and objects-structures dialectics which are at the core of structuralist praxeologies and need to be understood as dynamical processes.

5.1 The thread on the ring of decimal numbers and its task of type $T_{3}^{+}$(see $4.3)$

The thread that concerns us, entitled "decimal numbers", is visible at the following address:

http://www.les-mathematiques . net/phorum/read.php?3,318936, page=1. The discussion took place in 2007, probably during a short lapse of time. More information on the online forum are given in (Hausberger, 2016a). The initiator of the thread is called Mic, who puts forward two statements and two questions: $A_{1}\left(\mathbb{D}\right.$ is a subring of $\mathbb{Q}$ ), $A_{2}$ (Any subring of $\mathbb{Q}$ is a PID), $Q_{1}$ (How can we prove it?), and $Q_{2}$ (How do we define the greatest common divisor of two decimal numbers?).

From the outset, we note that the two statements $A_{1}$ and $A_{2}$ are the premises of a syllogism whose conclusion is "D is a PID", noted $A_{0}$, which is probably the result Mic is aiming at. The statement $A_{2}$ is a generalisation of $A_{0}$ (we note $A_{2}=A_{0}^{g}$ ) in the spirit of the structuralist method: the desired proof is located at the upper level of generality $\left(A_{0}^{g}\right)$, reflecting the practice of expert mathematicians who postulate that this generalisation carries simplification, and consider that it is illuminating as to the "root causes" behind the result (the principality of $\mathbb{D}$ ). The question $Q_{2}$ is also linked to $A_{0}$ : the existence of the gcd as well as the various definitions (or properties) of the gcd that can be stated all depend on the type of ring which is considered. An expanded discussion of the ring $\mathbb{D}$ together with such tasks as computing the gcd of two decimal numbers using different techniques may be found in (Hausberger, 2016a).

The investigation of question $Q_{1}$ will lead another participant, $b s$, to raise the mathematical discussion to an even higher level of generality and formulate the question $Q_{1}^{g}$ (Are all subrings of a PID also PIDs?). The participant barbu rasé then responds through an answer to a generalisation $Q_{1}^{g g}$ of the question: he gives a full class of counter-examples to the statement "Any remarkable property of a ring (Euclidean, PID, UFD, Noetherian, Bezout) is inherited by a subring". Another participant, Toto zero, brings forward the statement $A_{3}$ 
$(\mathbb{Z}[X]$ is not principal) in order to provide a counter-example to the universal statement underlying question $Q_{1}^{g}$. Then Olivier $G$ completes the argument by stating $A_{4}$ (The ideal $(2, X)$ of $\mathbb{Z}[X]$ is not principal).

The statement $A_{3}$ is actually the subject of a plurality of proofs, often as a draft followed by attempts of completion, which corresponds to a graduation in structuralist dimension (the three levels). I will now analyse these proofs more precisely and highlight the corresponding structuralist praxeologies.

5.2 The type of task $T_{3}^{-}$(show that a given ring is not a PID) in the case of $\mathbb{Z}[X]$

An elementary proof of $A_{3}$, via $A_{4}$, is to argue by contradiction and write $(2, X)=(P)$. This means that the ideal $(P)$ contains 2 and $X$, so that $P$ divides 2 and $X$ (the dictionary elements/structures is used here). By reasoning on the degree, it is shown that $P$ is a constant and then a unit of the ring $\mathbb{Z}$, i.e. \pm 1 . But an equality $1=2 U+X V$ is impossible in $\mathbb{Z}[X]$, as seen by evaluating at 0 , for parity reasons. The proof uses the property $\operatorname{deg}(P Q)=\operatorname{deg}(P)+\operatorname{deg}(Q)$ of the degree, valid in $A[X]$ for any integral domain $A$, which is a structural property linking a multiplicative and an additive structure. However, the conceptual dimension of the proof remains inconspicuous and does not involve structuralist techniques beyond logical and set-theoretic reasoning based on definitions of structures (the use of the dictionary).

A more conceptual reading of this proof, which also serves as a heuristic, is to question the properties of the elements 2 and $X$ : again with the degree map, it is easy to show that these are irreducible elements of the ring $\mathbb{Z}[X]$. In fact, the theory that guides the mathematical work is that of UFDs since it is known that $\mathbb{Z}[X]$ is a UFD ( $\mathbb{Z}$ is a UFD and this property is stable under transition to a polynomial ring). Why taking the number 2 ? Rings of the form $K[X]$, where $K$ is any field, are PIDs, thus primes of the ring $\mathbb{Z}$ must play a role. As units of $\mathbb{Z}[X]$ coincide with those of $\mathbb{Z}$ (a property valid for any ring $A[X]$, under the condition that $A$ is an integral domain), i.e. with \pm 1 , the two elements are not related (equal up to a unit), so they are mutually prime. These arguments explain why the ideal $(2, X)$ may be considered a good candidate to provide a non-principal ideal. Finally, if $\mathbb{Z}[X]$ was a PID, the ideal $(2, X)$ would be generated by a gcd, thus a unit. One concludes as before.

A final proof originates from the remark that the ideal $(X)$ is strictly included in the ideal $(2, X)$. This fact is then connected to the following wellknown structuralist theorem in Ring Theory: in a PID, any prime ideal is maximal (theorem $T h_{1}$ ). So it suffices to show that $(X)$ is a non-maximal prime ideal. A standard structuralist technique involves reasoning on the quotient $\mathbb{Z}[X] /(X)$ to show that it is an integral domain (thus $(X)$ is prime) but not a field (thus $(X)$ is not maximal, which we already know from the remark). This is again a dictionary, but on a higher level, since it involves two structures: the 
technology is based on the links between the properties of ideals and those of the quotient. Finally, this quotient may be interpreted as the addition of the relation $X=0$ to the ring $\mathbb{Z}[X]$ : the quotient ring is none other than $\mathbb{Z}$, up to isomorphism, which may be shown rigorously by using the so-called "first isomorphism theorem", a standard structuralist tool, applied to the evaluation map of polynomials at the point $X=0$. The properties referred to are stable by isomorphism, thus the proof is complete.

Let's formalise the proofs in praxeological terms. We have met two techniques to solve the task $T_{3}^{-}$:

$-\tau_{1}$ : show the existence of a non-principal ideal;

$-\tau_{2}$ : show the existence of a non-maximal prime ideal.

The technology $\theta_{1}$ associated to $\tau_{1}$ is restricted to the definition of a UFD in the elementary proof; by contrast, $\theta_{2}$ involves the theorem $T h_{1}$. The gain of using $\tau_{2}$ instead of $\tau_{1}$ in the case of the ring $\mathbb{Z}[X]$ is a switch from the consideration of $(2, X)$ to that of $(X)$, hence a simplification.

Subtasks should also be considered in order to describe the complete resulting praxeologies $P_{1}$ and $P_{2}$. In the first case, $\tau_{1}$ induces the subtask $s T_{1}$ : show that a given ideal of the form $(a, b)$ is not principal, with technique $\tau_{11}$ : assume $(a, b)=(\delta)$ and deduce from this set-theoretic equality as much information on $\delta$ as needed in order to produce a contradiction. The logos does not contain any structuralist theorem. On the contrary, the knowledge that $\mathbb{Z}[X]$ is a UFD, thus taking the theory of UFDs as the theory in ATD terms, orients the proof (this an echo of Bourbaki, cf my brief epistemological survey) and allows to use, instead of $\tau_{11}$, a technique $\tau_{12}$ : compute $\delta=\operatorname{gcd}(a, b)$ and show that $\delta \notin(a, b)$. The corresponding technology $\theta_{12}$ uses the theorem $T h_{2}$ : $\operatorname{gcd}(a, b)$ generates $(a, b)$ whenever it is a principal ideal. Developing the heuristic aspects of the elementary proof results in a considerable enrichment of the logos part, thus in the development of a praxeology with a higher structuralist dimension.

In the second case, $\tau_{2}$ induces the subtasks $s T_{2 a}$ (show that a given ideal $I$ is prime) and $s T_{2 b}$ (show that the latter is not maximal), with the following techniques $\tau_{22 a}$ (show that the quotient $A / I$ is isomorphic to an integral domain) and $\tau_{22 b}$ (show that the latter is not a field). We have already seen on our example that the technology $\theta_{22}$ for both techniques includes isomorphism theorems and the stability of the properties considered under ring-isomorphism. The computation of the gcd has been replaced by a more conceptual argument.

How did Mic and his fellows handle the task on the online forum? The technique $\tau_{1}$ was promoted by OlivierG, but Mic needed a tip by corentin in order to be able to apply $\tau_{11}$ successfully. One could suppose that Mic got lost in the middle of the several but basic set-theoretic and arithmetic steps that lead to the contradiction $1 \notin(2, X)$ whose statement was initially unknown. This wouldn't happen with technique $\tau_{12}$, but no participant on the forum introduced the gcd as a tool. As for the technique $\tau_{2}$, oumpapah sketched a proof but he neither proved the isomorphism $\mathbb{Z}[X] /(X) \simeq \mathbb{Z}$, nor 
gave any technological argument. Nevertheless, Mic could reconstruct part of the argumentation and brought forward $T h_{1}$.

The techniques $\tau_{11}$ and $\tau_{22 a}$ inspired another participant, Niktalop, who advocated that the contradiction sought after should be considered at the level of quotients $\mathbb{Z}[X] /(\delta) \simeq \mathbb{Z} / 2 \mathbb{Z}$, since $\mathbb{Z}[X] /(2, X) \simeq \mathbb{Z} / 2 \mathbb{Z}$. In a kind of bluff, he parted with a "I leave it for you to conclude". In this case, the transition to quotients does not bring any simplification (rather the opposite). This indicates that, in the process of acquisition of structuralist praxeologies, structuralist technologies (even if they are often repellent to a learner) may sometimes provoke a kind of fascination, and lead to the production of artificial and non-efficient praxeologies.

\subsection{Conclusions}

The study of the thread on the ring of decimal numbers has shown a great vitality of the following two fundamental and interrelated dialectics:

- Dialectic of the particular and the general. The reformulation of the problem at a higher level of generality (transition from $A$ to $A^{g}$ ) appears as an approach used repeatedly by the participants on the forum. This corresponds to expert practise of mathematicians in Abstract Algebra and contributes to the development of structuralist praxeologies.

- Dialectic of objects and structures. By the examination of the structure of objects, and of possible generalisations of statements and proofs, of the insertion of these generalisations into the axiomatically organised theory, abstract axiomatic structures may be applied as a conceptual generalisingsimplifying viewpoint in order to demonstrate properties on mathematical objects. Conversely, a semantic control of the formal general statements on structures is exercised by putting them to the test of known examples (objects). In this sense, the objects-structures dialectic may be regarded as a syntax-semantics dialectic. This point of view and its didactical consequences have been developed further in Hausberger (2017b) and in Hausberger (2016b). In particular, I explain in Hausberger (2017b) how the objects-structures dialectic may be worked out, from its epistemological origin, to become a didactical dialectic in the same sense as the tool-object dialectic (Douady, 1991).

It should also be noted that the participants in the forum make up a heterogeneous group. The study has shown the development of advanced structuralist praxeologies, but these are due to the more experienced practitioners. In a didactic situation, the division of the tasks into subtasks (such as $s T_{2 a}$ ) is often carried out by the teacher who also reverses the order of subtasks in comparison to the logic of discovery. A teacher might for instance ask: "show that $A / I \simeq B$; deduce from the latter that $I$ is prime". I make the assumption that students' lack of autonomy with the structuralist method, which is a heuristic, is a real obstacle when it comes to understanding the reasons 
for this division and thus to reconstruct a proof that contains a significant structuralist dimension.

Some of the arguments that guide the investigation of a mathematical problem (e.g. the fact that 2 and $X$ are irreducible elements of the UFD $\mathbb{Z}[X]$ ) are often superfluous in the writing of a proof (e.g. the elementary proof that $\mathbb{Z}[X]$ is not a PID, as sketched on the forum). I made these arguments explicit in my account of proofs, because they are crucial, for instance for working out the technique $\tau_{1}$ through the subtask $s T_{1}$ that requires to exhibit a suitable ideal. Wikipedia or other media generally point out $(2, X)$ without any indication of the reasons for that choice, and therefore the arguments remain implicit which results in a very poor logos part. This contrasts with the mathematical research praxeologies which include a heuristic dimension as a considerable enrichment of the logos part. This raises the ecological concern that didactical intervention (pointing out the candidate) may hinder the development of structuralist praxeologies. It suggests also that an instructional setting that enhances the heuristic dimension may favour their development. At the end of the paper, I will elaborate on the idea of a study and research path (Winsløw, Matheron, \& Mercier, 2013) anchored on the objects-structures dialectic, as a means to favour the development of structuralist praxeologiesr.

\section{Avenues of further research on the teaching and learning of Abstract Algebra}

The elaboration of a praxeological model of reference for Abstract Algebra around the key notion of structuralist praxeology aims at the following two main goals: the application of this model in order to acquire a better understanding of the transition problem(s) that occur in the learning of this abstract topic, and subsequently its application to inform didactical intervention and in particular nourish task-design as a research practise in university mathematics education. We will discuss these two points in this concluding section of the paper, as perspectives under development.

6.1 Praxeological analyses around structuralist praxeologies and the transition problem

I have presented Abstract Algebra, according to its historical and epistemological roots, as a conceptual rewriting of classical algebra or a formalisation of related mathematical domains (e.g. arithmetics): particular and concrete mathematical objects (e.g. a given ring $\mathbb{D}$, a given property of elements of such a ring) are viewed in the light of general, abstract structures. This is the objects-structures dialectic as a concrete-abstract dialectic. I have illustrated this dynamic with the example of the task $T_{3}^{+}$in the case of the ring $\mathbb{D}$ : show that $\mathbb{D}$ is a PID.

But the task $T_{3}^{+}$may also be applied to an abstractly defined class of rings. For example, let $A$ be a Noetherian integral domain such that every maximal 
ideal is principal; show that $A$ is a PID (task denoted $t^{\prime}$ ). In view of the objects-structures dialectic, the technique to deal with such a task will now involve the consideration of generic objects. From a cognitive point of view, the concrete-abstract dialectic takes place at a higher level. This phenomenon is well described by Benis-Sinaceur (2014, p. 93):

Usually, algebraic concepts produce knowledge when they are tied to facts and problems belonging to other mathematical areas, arithmetic, geometry, analysis, topology, etc., or belonging to an earlier stage of the algebraic trend itself, as it is, e.g. the case for the concept of group. If, on the other hand, an individual thing is understood in its objective links with other things, forming a coherent network, that means that it has been understood, realized, known, conceived concretly. In such a perspective we can understand how we may have a concrete knowledge of a highly abstract concept, as it happens especially in modern mathematics.

I will now formalise this idea in praxeological terms and draw connections with the curriculum in Abstract Algebra.

Algebraic structures often appear at the entrance at university, as merely a new vocabulary: the ring of integers, the fields $\mathbb{Q}, \mathbb{R}$ and $\mathbb{C}$, the algebra of polynomials. In a learning process, the type of task $T_{3}^{+}$is first encountered with individual rings such as $\mathbb{Z}$ and $K[X]$, where $K$ is a field, and accomplished using an elementary technique $\tau$ (see section 4.1). The technology is reduced to the definitions of structures. It is then emphasised that the proofs present similarities and that the key ingredient is the Euclidean division. Students thus replace $\tau$ with a structuralist technique $\tau_{s}$ : show the existence of a Euclidean algorithm. The logos block $\Lambda$ now includes a theorem on structures: every Euclidean ring is a PID (technological argument $\theta$ ) and the theory $\Theta$ in the sense of ATD is the mathematical theory of Euclidean rings. This is a first transition: from $\Pi=\left(T_{3}^{+}, \tau\right)$ to the complete structuralist praxeology $\left[\Pi_{s} / \Lambda\right]=\left[T_{3}^{+} / \tau_{s} / \theta / \Theta\right]$

The task $t^{\prime}$ of type $T^{\prime}$ (show that an abstractly-defined ring is a PID) appears in the textbook (Francinou \& Gianella, 1994) which is widely used by university students in France. It is addressed to Master degree students who are preparing the French Agregation (a competitive exam for prospective teachers for secondary and tertiary education). The authors have sampled classical exercises from Abstract Algebra and provide proofs. The technique $\tau^{\prime}$ proposed to solve $t^{\prime}$ (show that $A$ is a PID) involves the two following subtasks raised as intermediary questions:

- $s T_{1}$ : show that $A$ is a UFD;

$-s T_{2}$ : show that every non-zero prime ideal is maximal of the form $(p)$ with $p$ irreducible.

I will show that the practice block $\Pi^{\prime}$ of the structuralist praxeology that the authors of the book develop, is built on the logos block of structuralist praxeologies of the type $\left[\Pi_{s} / \Lambda\right]$. We have already seen that the type of 
task $T_{2}^{+}$(show that a given ring is a UFD) may be accomplished via $T_{3}^{+}$as its technique, with technological argument the theorem Th (Every PID is a UFD). We have also encountered the theorem $T h_{1}$ (In a PID, every nonzero prime ideal is maximal) in the technology of a structuralist praxeology associated with $T_{3}^{-}$. We recall that the elements/structures dictionary - another technological argument encountered before - states the following: in a PID, $p$ irreducible is equivalent to $(p)$ maximal. Finally, the ascending chain condition that defines a Noetherian ring is a generalisation of one of the two conditions of the criterion that characterises UFDs (thus again a technological argument in another praxeology involving $T_{2}^{+}$). Altogether, the praxeological analysis highlights numerous connections between $\Pi^{\prime}$ and the logos parts of structuralist praxeologies of the type $\left[\Pi_{s, i} / \Lambda_{i}\right]$.

To summarise, a student who is learning Abstract Algebra is confronted with two types of transitions that are related to those highlighted by Winsløw (2008) in his investigation of the secondary-tertiary transition in analysis and the Calculus-Analysis transition at university (see also Winsløw et al. (2014, p. 101)). Mimicking the diagram presented in loc. cit., we may draw the following figure:

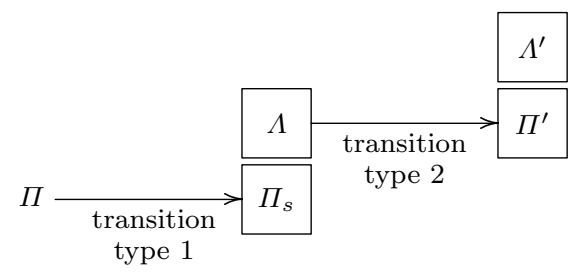

Fig. 1 Two types of transition in the Abstract Algebra curriculum at university for a student who is learning structuralist praxeologies

Although Algebra and Analysis involve quite different modes of reasoning, the transition from concrete to abstract thus presents similar challenges. But the following distinction should be pointed out: the type 1-transition in Winsløw's case is a process of completion of praxeologies, with praxis block unchanged, whereas in our context, $\Pi$ is replaced by $\Pi_{s}$ since structuralist techniques, oriented by the choice of a theoretical framework (a theory of structures), are developed. This new model, compared to the epistemologicallybased definition of structuralist praxeology given in the section 4.4, also contributes to clarify the transition from what was previously denoted $[T, *, *, *]$ to $\left[T^{g}, \tau, \theta, \Theta\right]$.

I make the assumption that a type 1-transition problem typically arises whenever the teacher adopts a "top-down" approach (see (Hausberger, 2016a) for more details), by setting out first the logos block $\Lambda$ and then more or less artificially connecting that part to a praxis blocks $\Pi_{s}$ that is, without referring to the praxis block $\Pi$ from which it historically originates, as a mean to high- 
light the rationale of the new concepts and techniques (e.g. giving a general proof that an Euclidean ring is a PID and setting up the task "prove that $\mathbb{Z}[i]$ is a PID" without investigating the case of $\mathbb{Z}$ first). By contrast, "bottom-up" approaches may be found in more recent textbooks (Cuoco \& Rotman, 2013). It is no surprise that the authors propose an historically-inspired approach to the teaching of modern algebra with Fermat's last theorem as a central thread. My future research will include an analysis of such a textbook, using my praxeological tools and a comparison with more standard textbooks. Such studies aim at giving a detailed account of the teaching of Abstract Algebra at university as it is, and as a byproduct at understanding the complex phenomenon of didactical transposition operated by the mathematician as a teacher of advanced topics.

I also make the assumption that a type 2-transition problem occurs whenever the $\left[\Pi_{s, i} / \Lambda_{i}\right]$ are not available in the praxeological equipment of the learner or the links between $\Pi^{\prime}$ and the $\Lambda_{i}$ are too weak. The students preparing the French Agrégation are taking capstones courses to recapitulate their mathematical knowledge. We may hypothesise that task $t^{\prime}$ has been chosen by the authors of the book for its connections with $\left[\Pi_{s, i} / \Lambda_{i}\right]$. Will the students manage to construct these links? A study of the first subtask $s T_{1}$ (Jovignot, Hausberger, \& Durand-Guerrier, 2017) has shown that the structuralist praxeology at stake decomposes into several structuralist sub-praxeologies interrelated with logical and algebraic praxeologies which are fundamental in order to make the structuralist technologies operative. This hidden complexity seems to be underestimated by the authors: we concluded from the analysis of the proof given by the authors that, although it is seen as a clear and synthetic account by mathematicians, it may appear quite inadequate for self-study (which was the goal of the textbook) by students who are not familiar with the structuralist methodology. This suggests that more didactic care should be given, in order to emphasise such ties between a $\Pi^{\prime}$ and some $\Lambda_{i}$, in a similar manner as the work carried out by Kondratieva and Winsløw (2017).

A more systematic investigation of structuralist praxeologies, in the case of the teaching and learning of the ideal concept at university, is currently being performed by Julie Jovignot.

\subsection{Instructional design in the ATD framework}

We will now deal with the teaching and learning of Abstract Algebra at university as it could be. I will briefly discuss a strategy for the development of structuralist praxeologies that is anchored in the preceding analyses.

In a study of the teaching and learning of mathematical modelling at university, Barquero et al. (2013) have identified constraints that hinder the development of mathematics as a modelling activity: applicationism (theory precedes applications, loc. cit. p. 317) as the dominant epistemology and monumentalism (contents are merely visited, while rarely questioned and problematised, loc. cit. p. 322; see also (Chevallard, 2012)) as the dominant pedagogy at 
university level. This relates to the "deductivist style" (Lakatos, 1976, p. 142) in academic mathematical texts. They subsequently made teaching proposals in terms of study and research paths (SRP; see also Winsløw et al. (2013)). A SRP is an inquiry process that takes the form of a series of questions and answers, starting from a generating question, and that takes place inside an appropriate experimental milieu (in the sense of non-intentional systems, see Brousseau (1997)) with an access to previously available-knowledge through some media. It is expected that, under suitable conditions that need to be investigated theoretically and empirically, such a process will enable students to reach the target knowledge with a good understanding of its raison d'être.

In a similar manner, the dominant "top-down" approach to algebraic structures as a theoretical discourse (conducive to contemplation, according to the etymology of theoria), contributes to situate the teaching and learning of Abstract Algebra at university in the "monumentalist paradigm". By contrast, I propose to discuss what could be a study of Abstract Algebra in the "paradigm of questioning the world" (Chevallard, 2012) that ATD is currently developing as a counterparadigm to monumentalism, using SRP.

Building on my epistemological model of reference, I support the view that questioning the world in Abstract Algebra should be similar to a study and research path (Bosch \& Winsløw, 2016) that fits into a "bottom-up" approach of the teaching of algebraic structures and present a good vitality of the particular-general and objects-structures dialectics (Hausberger, 2016c).

The first idea underneath this strategy is the following: formalisation is both a mathematisation of the world (the extra-mathematical reality) and, at a higher level of abstraction, a conceptual rewriting of previous (pre-structuralist) mathematics in terms of structures, usual mathematical objects being taken as the (intra-mathematical) reality. In this perspective, questioning the world with a fruitful dialectic between media and milieu (Chevallard, 2006, p. 29) amounts to questioning mathematical objects themselves in such a way that may be developed a fruitful dialectic between objects and structures. Structural concepts will thus be applied or even constructed during the study process, in the dynamics of questions and answers.

The second idea is that a study and research path may be appropriate to implement the heuristic dimension that is able to support the development of structuralist praxeologies (section 5.3). But several ecological concerns need to be addressed, in relation to the challenge of "self-sustained study and research processes" (Bosch \& Winsløw, 2016). For instance: what are good generating questions when abstraction and generality as vectors of comprehension and simplification are an instructional issue? How to enable a fertile dialectic between objects and structures?

The third idea, in a kind of response to these considerations in the case of the learning and teaching of the arithmetics of abstract rings, is to have the students work on a transcript of the thread on decimal numbers, which is thus used as a milieu. A didactical analysis of the potential of this media as a milieu has been previously undertaken (Hausberger, 2016a). The generating question for the study and research path was centred around $\mathbb{D}$ and more 
abstract structures in general that the students may extract from their study of the "media-milieu" (which includes Mic's initial question). Students have also been provided with tools (specific tags) in order to perform this analysis.

I cannot give a more detailed account of this experiment due to page limitation and direct the reader to (Hausberger, 2016a, 2016c) for a discussion of the results. They provide a first example of possible and innovative ways of designing tasks intended to develop the challenging structuralist praxeologies that have been identified and studied in this paper.

\section{References}

Barbe, J., Bosch, M., Espinoza, L., \& Gascón, J. (2005). Didactic restrictions on the teacher's practice: the case of limits of functions in spanish hish schools. Educational Studies in Mathematics, 59, 235-268.

Barquero, B., Bosch, M., \& Gascón, J. (2013). The ecological dimension in the teaching of mathematical modelling at university. Recherches en Didactique des Mathématiques, 33(3), 307-338

Beaulieu, L. (1993). A parisian café and ten proto-bourbaki meetings 1934-35. The Mathematical Intelligencer, 51(1), 27-35.

Benis-Sinaceur, H. (2010, March). Emmy Noether et l'école algébrique allemande dans le premier tiers du XXe siècle : mathématiques, style de pensée et philosophie. Communication aux Journées Noether, Lyon, France.

Benis-Sinaceur, H. (2014). Facets and Levels of Mathematical Abstraction. Philosophia Scientice, 18(1), 81-112

Bosch, M., \& Gascón, J. (2014). Introduction to the Anthropological Theory of the Didactic. In A. Bikner-Ahsbahs \& S. Prediger (Eds.), Networking Theories as a Research Practice in Mathematics Education (p. 67-83). Springer.

Bosch, M., \& Winsl $\varnothing w$, C. (2016). Linking problem solving and learning content: the challenges of self-sustained study and research processes. Recherches en Didactique des Mathématiques, 35(3), 357-401.

Bourbaki. (1950). The Architecture of Mathematics. American Mathematical Monthly, 4(57), 221-232.

Brousseau, G. (1997). Theory of didactic situations in mathematics. Dordrecht: Kluwer Academic Publishers.

Chevallard, Y. (2006). Steps towards a new epistemology in mathematics education. In M. Bosch (Ed.), Proceedings of the 4 th Conference of the European Society for Research in Mathematics Education (CERME 4) (p. 21-30). Barcelona: FUNDEMIIQS.

Chevallard, Y. (2012, July 8-15). Teaching mathematics in tomorrow's society: A case for an oncoming counterparadigm. Regular lecture presented in the 12th International Congress on Mathematical Education (ICME 12). COEX, Seoul (Korea).

Colmez, P. (2011). Eléments d'analyse et d'algèbre (et de théorie des nombres). Palaiseau: Les éditions de l'Ecole Polytechnique.

Corry, L. (1996). Modern Algebra and the Rise of Mathematical Structures. 2nd edition (2004). Basel: Birkhäuser.

Cuoco, A., \& Rotman, J. (2013). Learning modern algebra from early attempts to prove Fermat's last theorem. Washington: MAA textbooks.

Dorier, J.-L. (1995). Meta level in the teaching of unifying and generalizing concepts in mathematics. Educational Studies in Mathematics, 29, 175-197.

Douady, R. (1991). Tool, object, setting, window: elements for analysing and constructing didactical situations in mathematics. In A. Bishop, S. Mellin-Olsen, \& J. van Dormolen (Eds.), Mathematical Knowledge: Its Growth Through Teaching (p. 109-132). Dordrecht: Springer. 
Dubinsky, E. (1991). Reflective abstraction in mathematical thinking. In D. O. Tall (Ed.), Advanced Mathematical Thinking (p. 95-123). Dordrecht: Kluwer Academic Publisher.

Durand-Guerrier, V., Hausberger, T., \& Spitalas, C. (2015). Définitions et exemples : prérequis pour l'apprentissage de l'algèbre moderne. Annales de Didactique et de Sciences Cognitives, 20, 101-148.

Florensa, I., Bosch, M., \& Gascón, J. (2015). The epistemological dimension in didactics: Two problematic issues. In K. Krainer \& N. Vondrová (Eds.), Proceedings of the ninth congress of the european society for research in mathematics educationp (p. 26352641). Prague: Faculty of Education, Charles University.

Francinou, S., \& Gianella, H. (1994). Exercices de mathématiques pour l'agrégation. Algèbre I. Paris: Masson.

Gueudet, G. (2008). Investigating the secondary-tertiary transition. Educational Studies in Mathematics, 67(3), 237-254.

Guin, D. (2013). Algèbre II : Anneaux, Modules et Algèbre multilinéaire. Paris : EDP Sciences.

Hasse, H. (1930). Die moderne algebraische Methode. Jahresbericht der Deutschen Mathematiker-Vereinigung, 39, 22-34.

Hausberger, T. (2012). Le challenge de la pensée structuraliste dans l'apprentissage de l'algèbre abstraite : une approche épistémologique. In J.-L. Dorier \& S. Coutat (Eds.), Enseignement des mathématiques et contrat social, Enjeux et défis pour le 21e siècle, Actes du colloque EMF2012 (p. 425-434). Genève : Université de Genève.

Hausberger, T. (2013). On the concept of (homo)morphism: a key notion in the learning of Abstract Algebra. In B. Ubuz, C. Haser, \& M. A. Mariotti (Eds.), Proceedings of the Eight Congress of the European Society for Research in Mathematics Education (p. 2346-2355). Ankara: Middle East Technical University.

Hausberger, T. (2016a). Comment développer des praxéologies structuralistes en Algèbre Abstraite? Recherches en Didactique des Mathématiques, 36(1), 97-142.

Hausberger, T. (2016b). Enseignement et apprentissage de l'algèbre abstraite à l'université et premiers éléments d'une didactique du structuralisme algébrique. études croisées en didactique et épistémologique des mathématiques. Note de synthèse pour l'habilitation à diriger des recherches. Université de Montpellier. Retrieved from https://hal .archives-ouvertes.fr/tel-01408565

Hausberger, T. (2016c, January). Enseignement et apprentissage de l'algèbre abstraite à l'université : vers un paradigme du questionnement $d u$ monde. Communication at the 5th International Congress on ATD, Castro-Urdiales, Spain.

Hausberger, T. (2016d). A propos des praxéologies structuralistes en algèbre abstraite. In E. Nardi, C. Winsløw, \& T. Hausberger (Eds.), Proceedings of the 1st Congress of the International Network for Didactic Research in University Mathematics (p. 296305). Montpellier: University of Montpellier and INDRUM.

Hausberger, T. (2017a). The (homo)morphism concept: didactic transposition, metadiscourse and thematisation. International Journal of Research in Undergraduate Mathematics Education. To appear.

Hausberger, T. (2017b). La dialectique objets-structures comme cadre de référence pour une étude didactique du structuralisme algébrique. Education et Didactique. To appear, $11(2)$.

Jovignot, J., Hausberger, T., \& Durand-Guerrier, V. (2017, January). Praxeological analysis: the case of ideals in Ring Theory. Paper presented at the CERME10 conference, Dublin, Ireland.

Kondratieva, M., \& Winsløw, C. (2017, January). A praxeological approach to Klein's plan B: cross-cutting from Calculus to Fourier Analysis. Paper presented at the CERME10 conference, Dublin, Ireland.

Lakatos, I. (1976). Proofs and Refutations: The logic of mathematical discovery. Cambridge University Press.

Leron, U., \& Dubinsky, E. (1995). An Abstract Algebra story. American Mathematical Monthly, 102(3), 227-242.

Mandelbrojt, S. (1952). Pourquoi je fais des mathématiques. Revue de métaphysique et de morale, $57(4), 422-429$. 
Nardi, E. (2000). Mathematics Undergrates' Responses to Semantic Abbreviations, Geometric Images and Multi-level Abstractions in Group Theory. Educational Studies in Mathematics, 34, 169-189.

Perrin, D. (1996). Cours d'algèbre. Paris: Editions Ellipses.

Piaget, R., J. ad Garcia. (1989). Psychogenesis and the history of science. New York: Columbia

Robert, A. (1987). De quelques spécificités de l'enseignement des mathématiques dans l'enseignement post-obligatoire. In Cahier de didactique des mathématiques 47. Paris: IREM de Paris 7.

Sfard, A. (1991). On the dual nature of mathematical conceptions: reflection on processes and objects as different sides of the same coin. Educational Studies in Mathematics, 22(1), 1-36.

van der Waerden, B. L. (1930). Moderne Algebra. 2 vols. Berlin: Springer.

Winsløw, C. (2008). Transformer la théorie en tâches : la transition du concret à l'abstrait en analyse réelle. In R. Rouchier \& al. (Eds.), Actes de la XIIIıème Ecole d'Eté de Didactique des Mathématiques (p. 1-12. Cédérom). Grenoble : La Pensée Sauvage.

Winsløw, C., Barquero, B., De Vleeschouwer, M., \& Hardy, N. (2014). Study and research courses as an epistemological model for didactics. Research in Mathematics Educations, 16(2), 95-111.

Winsløw, C., Matheron, Y., \& Mercier, A. (2013). Study and research courses as an epistemological model for didactics. Educational Studies in Mathematics, 83(2), $267-284$ 